\title{
RIGHT RENAL VEIN THROMBOSIS WITH POST REVERSIBLE ENCEPHALOPATHY SYNDROME WITH RIGHT ATROPHIC KIDNEY IN A NEONATE
}

\author{
Shubhi Verma1, Gunjan Kela Mehrotra², Rashmi Parihar ${ }^{3}$, Keval Kishore Arora ${ }^{4}$
}

1 Junior Resident, Department of Paediatrics, SAMC and PGI, Indore, Madhya Pradesh.

${ }^{2}$ Associate Professor, Department of Paediatrics, SAMC and PGI, Indore, Madhya Pradesh.

$3 J u n i o r$ Resident, Department of Paediatrics, SAMC and PGI, Indore, Madhya Pradesh.

${ }_{4}^{4}$ Assistant Professor, Department of Paediatrics, SAMC and PGI, Indore, Madhya Pradesh.

HOW TO CITE THIS ARTICLE: Verma S, Mehrotra GK, Parihar R, et al. Right renal vein thrombosis with post reversible encephalopathy syndrome with right atrophic kidney in a neonate. J. Evolution Med. Dent. Sci. 2018;7(18):2298-2299, DOI: $10.14260 /$ jemds/2018/517

\section{PRESENTATION OF CASE}

A 14-day male child with apparently normal birth history was brought with history of faulty feeding followed by high-grade fever and gross haematuria since 4 - 5 days with decreased feeding. The baby came to us with signs of dehydration and rapid breathing with signs of sepsis. Clinical examination was suggestive of large palpable right kidney. Baby was admitted with us for dehydration and treatment with IV fluids was given. Initial investigations were suggestive of thrombocytopenia with positive CRP, raised BUN and creatinine and deranged coagulation profile with hypernatraemia. IV antibiotics were given for management of septicaemia. The baby required prolonged antihypertensives for control of blood pressure during the total stay of 1 month. The coagulation profile was altered for long duration. We planned to continue antihypertensives and heparin for 3 to 6 months with regular monitoring. Our patient is now three months old with well controlled blood pressure. We were successfully able to stop antihypertensives at 3 months of age.

\section{PATHOLOGICAL DISCUSSION}

USG KUB was suggestive of acute kidney nephropathy due to right renal vein thrombosis [Figure 1, 2 and 3]. Baby also had hypertension with persistent haematuria and deranged coagulation profile, for which subcutaneous enoxaparin was started along with anti-hypertensives (Oral nifedipine and oral clonidine). Soon baby was started on breastfeeds as the clinical condition improved. MRI brain was done in view of persistent dullness (? uraemic encephalopathy), which was normal. Repeat renal function tests were normal, but renal Doppler on review after the treatment of 10 days was suggestive of right atrophic kidney. Baby was discharged on anti-hypertensives and enoxaparin with plan to continue and taper off over next 6 months. On subsequent follow-up over 3 months, we were successfully able to taper off these medications. We have planned to monitor renal functions regularly. Some patients with renal vein thrombosis may require life-long antihypertensives with regular monitoring of renal functions. Long-term enoxaparin may also be required. This may have a poor prognosis.

'Financial or Other Competing Interest': None.

Submission 21-03-2018, Peer Review 12-04-2018,

Acceptance 20-04-2018, Published 30-04-2018.

Corresponding Author:

Dr. Gunjan Kela Mehrotra,

\#201, A-Block, Om Gurudev Complex,

SCH-54, Vijay Nagar, Indore-452010, Madhya Pradesh.

E-mail: drgunjankela@yahoo.com

DOI: $10.14260 /$ jemds $/ 2018 / 517$

\section{(c) $(7)$}

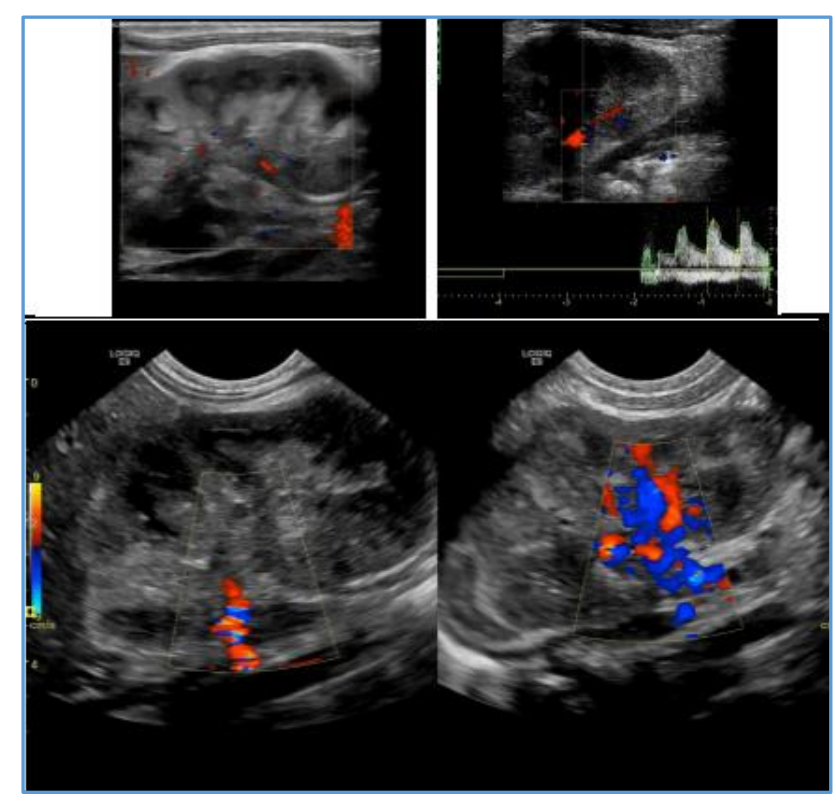

Figure 1, 2 and 3. USG Colour Doppler shows Decreased Blood Flow to Right Kidney

\section{DIFFERENTIAL DIAGNOSIS}

In renal vein thrombosis most common differential diagnosis are prematurity, central venous lines, diabetic mother, asphyxia, infections, dehydration, polycythaemia, reduced renal blood flow due to shock and hyperosmolality, congenital heart disease and congenital deficiency of anticoagulants. In our patient, the cause was dehydration and sepsis.

\section{DISCUSSION OF MANAGEMENT}

Renal vein thrombosis (RVT) is the second most common cause of thromboembolism in neonates after umbilical vein thrombosis with incidence of $10 \%$ of neonatal venous thromboembolism.[1] It is more common among male infants with occlusion being unilateral more than bilateral with most common causes including prematurity, central venous lines, diabetic mother, asphyxia, infections, dehydration, polycythaemia, reduced renal blood flow due to shock and hyperosmolality, congenital heart disease and congenital deficiency of anticoagulants.[1,2,3,4] Incidence of unilateral RVT due to sepsis is $6 \% .{ }^{[2]}$

Renal vein thrombosis is reported to be more common among male infants with ratio of 2:1.[2] Incidence of occlusion is more for left kidney.[3,5,6] Our case was a male child with RVT on right side. Most common associated causes in decreasing order of incidence are prematurity (54\%), central venous lines $(17 \%)$, diabetic mother $(13 \%)$, asphyxia $(6 \%)$ 
and infections (6\%) according to a study conducted in 2004.[3] Other causes include dehydration, polycythaemia, reduced renal blood flow due to shock and hyperosmolality, congenital heart disease and deficiency of anticoagulants like protein $\mathrm{C}$ and $\mathrm{S}$, Antithrombin III, factor $\mathrm{V}$ Leiden mutation and prothrombin mutation. $[1,2,3,4]$ A review of the literature showed that RVT of the new-born might be of unknown aetiology and probably occurs before birth.[7,8] Genetic mutations such as factor $\mathrm{V}$ Leiden is a risk factor, especially for in utero RVT.[9,10] Other risk factors include prolonged central venous cannulation, hereditary thrombophilia, trauma, burns and Wilms' tumour.[11,12,13,14] In the adult and children it is often a silent complication of the nephrotic syndrome, the hypercoagulability of which may be an important factor in the pathogenesis of the thrombosis.[15,16,17] Incidence of unilateral renal vein thrombosis due to sepsis is 6\%.[3] Our case was diagnosed by signs and symptoms of haematuria, acute renal failure, hypertension, thrombocytopenia, clinical examination revealing right nephromegaly and renal Doppler suggestive of reduced renal blood flow with cause being sepsis and dehydration. [5] Ultrasonography with colour Doppler is important for diagnosis of RVT.[1,5] Our case was managed with treatment of sepsis, hypertension and use of subcutaneous anticoagulant. But baby eventually developed atrophy of the affected kidney. A study conducted in 2015 has shown that damage to kidney due to poor perfusion resulted in poor prognosis. ${ }^{[6]}$

\section{REFERENCES}

[1] Sujatha R, Hidayathulla M, Rajeev R. A case of renal vein thrombosis with adrenal haemorrhage. Sri Lanka J Child Health 2014;43(3):174-6.

[2] Anochie IC, Eke F. Renal vein thrombosis in the neonate: a case report and review of the literature. J Natl Med Assoc 2004;96(12):1648-52.

[3] Kuhle S, Massicotte P, Chan A, et al. A case series of 72 neonates with renal vein thrombosis. Data from the 1800-NO-CLOTS Registry. Thromb Haemost 2004;92(4):929-33.

[4] Singh M. Renal disorders. Care of the newborn. $8^{\text {th }}$ edn. Noida: HT Media Ltd., 2015: p. 406.

[5] Kosch A, Kuwertz-Broking E, Heller C, et al. Renal venous thrombosis in neonates: prothrombotic risk factors and long-term follow-up. Blood J 2004;104(5): 1356-60.
[6] Szafranska A, Pajak A, Killis-Pstrusinska K, et al. Renal vein thrombosis in a newborn with abnormal factor VIII level: clinical case report. Medicine (Baltimore) 2015;94(31): e1197.

[7] Rosendaal FR. Thrombosis in the young: epidemiology and risk factors. A focus on venous thrombosis. Thromb Haemost 1997;78(1):1-6.

[8] Wilkinson AG, Murphy AV, Stewart G. Renal venous thrombosis with calcification and preservation of renal function. Pediatr Radiol 2001;31(3):140-3.

[9] Ozyurek E, Besbas N, Aslan D, et al. Trauma as a risk factor for thrombosis in children: a report of three cases. Turk J Pediatr 2003;45(2):167-9.

[10] Zigman A, Yazbeck S, Emil S, et al. Renal vein thrombosis: a 10-year review. J Pediatr Surg 2000;35(11):1540-2.

[11] Pippus KG, Giacomantonio JM, Gillis DA, et al. Thrombotic complications of saphenous central venous lines. J Pediatr Surg 1994;29(9):1218-19.

[12] Argyropoulou Ml, Giapros VI, Papadopoulou F, et al. Renal venous thrombosis in an infant with predisposing thrombotic factors: color Doppler ultrasound and MR evaluation. Euro Radiol 2003;13(8):2027-30.

[13] Waymack JP, Tweddell JS, Warden GD. Renal vein thrombosis in burned children. J Burn Care Rehabil 1988;9(5):472-3.

[14] Ritchey ML, Othersen HB Jr, De Lorimier AA, et al. Renal vein involvement with nephroblastoma: a report of the National Wilm's Tumor Study-3. Eur Urol 1990;17(2):139-44.

[15] Louis CU, Morgenstern BZ, Butani L. Thrombotic complications in childhood-onset idiopathic membranous nephropathy. Pediatr Nephrol 2003;18(12):1298-300.

[16] Cameron JS. The nephrotic syndrome and its complications. Am J Kidney Dis 1987;10(3):157-71.

[17] Etoh T, Ohsawa I, Fujita T, et al. Nephrotic syndrome with portal, splenic and renal vein thrombosis. A case report. Nephron 2002;92(3):680-4. 